\title{
ACE polymorphism and COVID-19 outcome
}

\author{
Joris R. Delanghe $\mathbb{D}^{1} \cdot$ Marijn M. Speeckaert ${ }^{1} \cdot$ Marc L. De Buyzere $^{1}$
}

Received: 1 July 2020 / Accepted: 1 August 2020 / Published online: 7 August 2020

(c) Springer Science+Business Media, LLC, part of Springer Nature 2020

With interest with read the paper by Hatami et al. on angiotensin converting enzyme 1 (ACE1) I/D polymorphism and the recovery rate in COVID-19. Although we agree that genetics play a role in COVID-19 prevalence and mortality [1-3], we disagree with various aspects (quality and representativity of the genotype distribution studies enroled, some epidemiological data) of the statistical analysis, which has been carried out in the paper.

The basic data set on the ACE1 I/D genotype distribution contains several data, which are in disagreement with the Hardy-Weinberg equilibrium. For China $\left(\chi^{2}=448.27\right)$, Denmark $\left(\chi^{2}=12.68\right)$, and South Korea $\left(\chi^{2}=48.77\right)$, very high chi-square values can be calculated (for two degrees of freedom), which is pleading for either a strong selection bias or a genotyping error and should therefore have been designated as low-quality studies. Some referred studies (e.g., Ireland, Israel, Brazil, Denmark, Finland, Portugal, Serbia) are very small and are therefore characterized by very important estimation errors. The quality of the metaanalysis has not been verified by Hatami et al. and a sensitivity analysis for the good quality studies is lacking, which has important consequences for the meta-regression analysis. Moreover, a funnel plot symmetry analysis would have been welcome.

During the pandemic, China has adjusted the diagnostic criteria for COVID-19 (on Feb 12) and has corrected the mortality data (on April 16, which is after the analysis of Hatami et al. was made (April 2)), which makes comparison of data more difficult. Moreover, data of some multi-ethnic or immigration countries have been included, which are not representative for an entire country, showing highly internally variable ACE I/D genotype distributions (e.g., South Africa, Brazil, Canada, USA). Furthermore, in some countries, important regional differences in COVID-19

Joris R. Delanghe

joris.delanghe@ugent.be

1 Ghent University, Ghent, Belgium prevalence and mortality have been reported (e.g., Italy, where the Northern region Lombardy was struck more severely and the authors have used data from other parts of the country). The authors have used the I/D allele ratio value of 0.49 for Italy, which strongly differs from the average obtained in Italian studies over the last two decades (D allele $0.57-0.61$ corresponding to I/D allele ratios of $0.64-0.75)$.

As only $40 \%$ of the total variance of mortality due to COVID-19 can be explained by the ACE1 I/D polymorphism [3], also other confounders (e.g., demography, seasonality, local health care organisation) must be taken into account when analyzing survival rates in COVID-19 infection.

The ACE1 I/D polymorphism is also functionally linked to the related enzyme ACE2 [2], which is the natural receptor for the COVID-19 virus. Genetic polymorphisms for ACE2 have recently been described [4-6]. Both ACE1 and ACE2 are linked to hypertension, a well-known risk factor in COVID-19 [7].

In conclusion, only data matching with a sufficient quality should be used for the meta-regression analysis. Failure to do so may lead to unwarranted conclusions.

\section{Compliance with ethical standards}

Conflict of interest The authors declare that they have no conflict of interest.

Publisher's note Springer Nature remains neutral with regard to jurisdictional claims in published maps and institutional affiliations.

\section{References}

1. N. Hatami, S. Ahi, A. Sadeghinikoo, M. Foroughian, F. Javdani, N. Kalani, M. Fereydoni, P. Keshavarz, A. Hosseini, Worldwide ACE (I/D) polymorphism may affect COVID-19 recovery rate: an ecological meta-regression. Endocrine 68(3), 479-484 (2020). https:// doi.org/10.1007/s12020-020-02381-7

2. J.R. Delanghe, M.M. Speeckaert, M.L. De Buyzere, The host's angiotensin-converting enzyme polymorphism may explain 
epidemiological findings in COVID-19 infections. Clin. Chim. Acta 505, 192-193 (2020). https://doi.org/10.1016/j.cca.2020.03.031

3. J.R. Delanghe, M.M. Speeckaert, M.L. De Buyzere, COVID-19 infections are also affected by human ACE1 D/I polymorphism. Clin. Chem. Lab. Med. 58(7), 1129-1130 (2020). https://doi.org/ 10.1515/cclm-2020-0605

4. Q. Chen, X. Tang, C.-q Yu, D.-f Chen, J. Tian, Y. Cao, W.-y Fan, W.-h Cao, S.-y Zhan, J. Lv, X.-x Guo, L.-m Li, Y.-h Hu, Correlation of angiotensin-converting enzyme 2 gene polymorphism with antihypertensive effects of benazepril. Beijing Da Xue Xue Bao 42, 293-298 (2010)

5. Y. Luo, C. Liu, T. Guan, Y. Li, Y. Lai, F. Li, H. Zhao, T. Maimaiti, A. Zeyaweiding, Association of ACE2 genetic polymorphisms with hypertension-related target organ damages in south Xinjiang. Hypertens. Res. 42(5), 681-689 (2019). https://doi.org/10.1038/ s41440-018-0166-6

6. Y. Cao, L. Li, Z. Feng, S. Wan, P. Huang, X. Sun, F. Wen, X. Huang, G. Ning, W. Wang, Comparative genetic analysis of the novel coronavirus (2019-nCoV/SARS-CoV-2) receptor ACE2 in different populations. Cell Discov. 6, 11 (2020). https://doi.org/10. 1038/s41421-020-0147-1

7. C.A. Devaux, J.M. Rolain, D. Raoult, ACE2 receptor polymorphism: susceptibility to SARS-CoV-2, hypertension, multiorgan failure, and COVID-19 disease outcome. J. Microbiol. Immunol. Inf. 53(3), 425-435 (2020). https://doi.org/10.1016/j. jmii.2020.04.015 